\title{
Mobile as a Means to Electrification in Uganda
}

\author{
Jennifer Zamora \\ Google, Inc. \\ Mountain View, USA \\ zamora@google.com
}

\begin{abstract}
This research study investigates a proposed model using mobile phones as an accelerator for solar adoption in Uganda. Sixty-five percent of Uganda is non-electrified, and $72 \%$ of people are unbanked. Due to the lack of financial infrastructure and banking history, banks are not able to predict default loan behaviors. In an attempt to scale solar adoption, we propose a USSD model for users to receive energy loan approvals based on mobile financial history. The research involves a mix-method qualitative approach with 36 users to evaluate the following objectives: 1) user's ability to understand and consent to a "mobile credit check" for loan approval 2) perception of variable loan discounts for those with good credit and 3) how the USSD model will fit in the broader solar environment.
\end{abstract}

\section{Author Keywords}

Mobile; Energy; Solar; Microfinance; Uganda; East Africa

\section{ACM Classification Keywords}

H.5.m. Information interfaces and presentation (e.g., HCI): Miscellaneous

\section{INTRODUCTION}

Uganda is among the 20 countries with the highest electricity access deficit [19]. Access to electricity is estimated to be in reach for $18 \%$ of the $37.5 \mathrm{M}$ people in Uganda, and large-scale efforts like the United Nation's Sustainable Development Goals (SDG) aim to address this by ensuring access to sustainable energy for all $[15,16]$. There is an opportunity to use mobile technology to accelerate adoption of sustainable energy like solar power. Financial limitations like low-income rates and poor infrastructure impede the growth of electrification. People often need loans to afford grid or solar connection. Financial institutions often have little to no information about a person who applies for a loan due to the high rates of unbanked individuals $[9,14]$. Notable strides have been made to predict loan payment behaviors for individuals that are unbanked and this is undoubtedly a benefit for banks,

\footnotetext{
Permission to make digital or hard copies of part or all of this work for personal or classroom use is granted without fee provided that copies are not made or distributed for profit or commercial advantage and that copies bear this notice and the full citation on the first page. Copyrights for thirdparty components of this work must be honored. For all other uses, contact the Owner/Author.

Copyright is held by the owner/author(s).

AfriCHI'16, November 21-25, 2016, Nairobi , Kenya

ACM 978-1-4503-4830-0/16/11.
}

http://dx.doi.org/10.1145/2998581.2998603 solar lenders, and borrowers. The ability to evaluate creditworthiness based on common mobile behavior patterns has been found to be as effective as the traditional credit scoring methods in developed markets [2].

Two areas that remain unexplored are the process for how this model will be implemented, and what implications exist for the borrower. In this study, we investigate the design of a proposed loan approval process through a USSD (Unstructured Supplementary Service Data) menu system via feature phone. This is defined as a communication technology used to send text between a mobile phone and an application program in the network. We define feature phone as a mobile device that cannot download third party apps, and does not have a data plan. The proposed flow will be used for solar loan approval through a series of USSD interactions. The process will require the borrower to authorize access to their mobile financial history and personal data for loan qualification to the organizations involved, such as the bank, solar company and data analysis partner. The solar shop will receive a notification of approval or rejection for the loan request. If the borrower is approved, the solar shop representative can provide the solar kit to the borrower, and monthly payments will be handled through mobile money transactions until the debt is paid in full. The results of this research provide insights for the following objectives: 1) user's ability to understand and consent to a "mobile credit check" for loan approval 2) perception of variable loan discounts for those with good credit and 3) how the USSD model will fit in the broader solar environment.

The paper starts by covering background and relevant work about the complexities of solar and mobile financing. Following is an outline of the research methodology and findings from the qualitative insights. After the results we discuss the implication for the findings and wrap up with future work.

\section{BACKROUND}

There are various obstacles in this market that make scaling energy connectivity challenging. According to the World Bank, getting electricity in Uganda can require a six-step procedure takes 132 days and costs $11004.9 \%$ of income per capita [17]. In comparison, solar offers energy connections at more feasible rates depending on the size and power of the solar kit; however, the costs of a typical solar kit are often substantial enough to warrant a loan, especially for those far away from the power grid. Banking activity is fairly low as it is estimated that approximately 
$28 \%$ of the adult population in Uganda has an active account with a financial institution $[14,18]$.

Mobile technology has the potential to support regions with undeveloped financial infrastructure by providing data used to predict payment behavior. Data from Groupe Spécial Mobile Association (GSMA) and World Bank suggest that there are more active mobile money accounts than active bank accounts in Uganda $[14,18]$. Among adults in Uganda, mobile money penetration is between $29 \%-35.1 \%$, well above the average for the rest of Sub-Saharan Africa at $12 \%$ $[8,10]$. Mobile phone usage is also growing, with more than $60 \%$ of people subscribed to mobile in 2015 .

\section{RELATED WORK}

Mobile can be a solution for infrastructure and assessing payment risk. A unique identifier like an official identification document is needed for banking transactions such as a loan. Uganda recently established a national ID system that has not yet fully penetrated the population [3]. Using mobile accounts can fulfill this requirement and as people conduct electronic transactions on mobile, they develop financial histories. This documented mobile financial history can potentially be used to evaluate credit risks, like that of credit scoring in developed markets $[2,6]$. Mobile data indicators have been found to predict loan behavior; for example, high mobility (calls from geographically dispersed towers) and larger social networks were indicators of lower default rates [2]. The bank involved in this study determined that with this data, they could eliminate up to $43 \%$ of default loans [2].

There are limitations of using mobile network logs as predictors for loan default behavior since they may not be reliable for all cases. In a longitudinal study exploring complexities in solar charging environments, we see potential gaps between documented mobile data and actual user behavior; for example, like using another person's phone or switching a device off, which hinders cellular tower tracking [1].

USSD is a versatile mobile application that is capable of reaching owners of low-end mobile devices. Various mobile application designs like USSD, Interactive Voice Response (IVR), and Short Message Service (SMS) have been evaluated and USSD has been identified as having the best fit for the model we are proposing in this paper. In comparison to IVR and SMS, USSD offers greater scalability and more security $[12,13]$. However, it is worth acknowledging possible security risks as the USSD model uses Global Systems for Mobile (GSM), and GSM security is known to have inherent weaknesses in its encryption and authentication algorithms [11].

\section{METHODS}

This research involved a mix of qualitative methods, including semi-structured 1:1 interviews and group discussions with 36 participants in Uganda. Sessions were conducted within a two-hour drive from Kampala in:
Luwero, Jinja, Wakiso, Mukono, and Mpigi. These regions were selected to sample a mix of local neighborhoods that have targeted income rates, reasonable population density, Luganda speakers for ease of translation, and accessible roads for transportation feasibility.

\section{Participant Demographics}

All participants are between 20-45 years old and actively used a feature phone and mobile money for the last 6 months or longer. We included a mix of genders including 17 females and 19 males, who were all recruited through a local research agency. We interviewed users with a mix of employment backgrounds. Most participants have multiple sources of income, like selling produce, bricks, clothes, etc. Many of these sources were highly variable, making their incomes unstable. The monthly income range was 281,265 744,525 UGX with an average of 539,367 UGX (roughly 85 - 255 USD, average 163 USD).

Of the 36 participants, six currently use solar kits at home as their primary source of electricity. The intent of this subset was to understand the experience of obtaining a solar kit, the decision making process, and a retrospective reflection on the proposed model.

\section{Session Structure}

The sessions were 1.5 - 2 hours long, and attendees included an assigned note taker, moderator and translator. The interviews were in Luganda with live translation in English. We also audio recorded the interviews, and the local research agency provided transcripts.

In order to explore the fit of the proposed model in practical use, we discussed solar and financial topics relevant to validating the overall flow. Specifically, we wanted to understand perception of solar brands, financial institutions, and current energy expenditure (i.e. candles, matches, batteries, kerosene). In addition to discussing solar awareness and financial experiences, participants were asked to engage in a narrative walkthrough of the proposed USSD system as we discussed each step. USSD mocks were explored but translation quality and literacy rate were obstacles that hindered our confidence in this approach. Rather than focusing on the legality of terms we wanted to validate the concept.

\section{The Proposed USSD System}

1. User enters local solar shop

2. User identifies the desired solar kit

3. Solar shop representative explains loan process

4. User starts USSD system on their feature phone

5. User provides consent to data sharing with financial and partner institutions providing loan

6. Institution validates qualification via database

7. User is approved or rejected

8. If qualified, user pays for solar kit deposit, goes home with ability to connect to energy source, and makes 
scheduled payments through mobile money until solar kit loan is paid off

\section{Data Collection and Analysis}

During the participant sessions we took copious notes and recorded audio. A group debrief followed each interview, with three to four researchers participating. The open coded analysis was broken down by step in the USSD flow to identify themes across participants. High-level themes were noted and modified throughout the duration of the study to track emerging insights and to iterate the interview script between participants.

Ending the study was a two-day workshop with eight team members participating in summarizing the findings. We reviewed transcripts and engaged in exercises to facilitate discussions. Thought exercises included empathy mapping and affinity diagrams for key topics like solar, mobile, and financing. Through thematic analysis we were able to develop themes as part of our final output.

\section{FINDINGS}

\section{Understanding of Mobile Financial History}

The idea of mobile financial history was new for most of the participants. There were three categorized perceptions for how users interpreted mobile financial history.

"My past loans that I have paid off." The most common perception was that mobile financial history content would capture all past financial transactions. This included savings, sending or receiving mobile payments, and loans of any sort. Whether it was a loan from a financial institution or small lending group, participants believed these financial transactions would be documented and shared as part of the mobile financial history check.

"They would see how much mobile money I have." The second most common perception was that mobile financial history was limited to mobile transactions. This included savings, and sending or receiving mobile payments.

"I am not sure." A few participants were not able to identify what a mobile financial history check would entail. This concept was very unclear for this set of respondents as the idea of evaluating someone for a loan based on mobile account information was novel.

\section{Perception of Variable Loan Discounts}

Participants were presented with a scenario of evaluating the concept of variable loan discounts. In this case a variable loan discount is when a person is approved for a solar kit loan, and receives a discount on the total cost because of their "good credit." In this case, "good credit" is based on mobile money historical data.

Participants were asked to imagine that they qualified for the solar kit loan, but were not offered the same discount that a friend who recently received a solar kit loan told them about. Many participants felt they are in no position to turn down the loan, regardless of discount, since they are the ones asking for money. Participants also felt that there would be no reason they would not receive the same discount since they view their financial history as positive, even those who mentioned past loan defaults. The perceived fairness of discounts for those with good credit history was mixed as some users felt it was not appropriate to include the past or treat people differently.

“This would be like parenting favoritism.” (P6)

"Why would they look at past loans? They do not know if I was cheated.” (P24)

\section{Broader Energy Environment}

Exposure to solar was not as prevalent as grid connection exposure where participants have access to the power grid through sources like charging kiosks or neighbors who have electricity. There was a weak understanding of solar brands and basic solar functionality in comparison to grid electricity. Every participant knew of Umeme as the energy distributor of Uganda, while in contrast most participants were not able to identify a solar company by name. Rather than identifying a solar kit brand, most were able to identify a place where they have seen one.

“There's a shop I've seen. They have them outside.” (P22)

"My neighbor has one so I would ask them about it." (P21)

Even among the solar user subset, solar brand recognition was low. Those who had solar kits said they obtained them after learning about solar through a channel other than the solar brand. These include a referral from a member of the community, familiar radio show advertisement with toll free number to access, or MTN (popular mobile money brand) partnership with a solar provider. Communicating through these trusted sources can increase awareness of the proposed USSD model as a financial option.

Part of the discussion exercise included evaluating the total expenditure of energy costs as one data point to assess financial loan fit. For example, we found the average participant spends 14,790 UGX (4.37 USD) a month on energy resources like candles, matches, batteries, and kerosene. In theory, this cost could go towards solar kit loan payments and has potential to act as one data point for loan fit. We found two issues with this energy assessment. First, many participants were not able to easily identify the total costs of energy expenditure on a weekly or monthly amount. This information will need to be calculated one resource at a time. Second, we found that current solar users were still spending money on these resources in addition to the solar kit payments. As a result, we cannot assume current energy costs will displace another energy cost like solar loan payments.

\section{DISCUSSION}

Mobile Data as a Loan Qualifier

Providing an institution with personal data such as mobile financial information was seen as acceptable when applying 
for a loan. This is validated by the fact that the borrower is the one requesting money from the bank, and the information requested is relevant.

"I wouldn't have any problem with it because the bank needs proof that I have capacity to pay back." $(P)$

We don't see any problem with it. The one with a bad financial history will know that he needs to make a better history next time." (P3)

There are concerns for false negative loan rejections. The intent of the proposed USSD model is to help facilitate smart financial lending between those who want energy connectivity and those who offer the service. We want to prevent loan default rates and repossession by ensuring borrowers can qualify for loans within their means. A flaw in the design of the model is that some borrowers may be unfairly denied access through this loan approval process whether by errors in the data, lack of financial history, or abstract use cases. For example, an abstract use case can include shared mobile devices or undocumented mobile money transactions. Participants have acknowledged these flaws.

"What happens if I don't have any account in any bank and if the bank does not get my financial history?" (P19)

"But I don't do all mobile money transaction with my phone. I only receive money especially from my husband but when I want to send money I use an agent." (P7)

The idea of using mobile financial history as a credit check for loan approval is a new concept and leaves room for interpretation without proper explanation. The concept can be interpreted as a mobile financial transaction check or as a financial transaction check done through mobile. As the user must provide informed consent, it will be ethically critical for staff members to make it clear that the authorization is for multiple organizations involved and includes personal data from mobile money transactions, savings, and potentially bank transactions if the user has an account with the bank partner.

There is sensitivity surrounding variable loan discounts. Based on the power of word-of-mouth among peers, there is potential for the variable loan discounts experience to upset some individuals. The concept of variable loan discounts was understood, but if an individual feels unjustly treated this may feed into the already negative perception of loan engagements, and unpredictability of unfamiliar services. Handling this with care and meaningful explanations could reduce feelings of resentment.

\section{Solar Environment Implications}

Staff training will be fundamental. Strong interest from partners will be key in order to successfully scale this effort. As seen in past research for agricultural loans, support and training provided for representatives greatly impacts the ability to support and execute the loan process [7]. In addition to this, it is important that the incentive model does not conflict for representatives approving loans. As seen in research for Centenary Bank, and anecdotal interviews with solar shop representatives while in the field, there are sales models that incentivize reps to approve of loans beyond the individual's loan potential which would defeat the purpose of the loan approval criteria [5].

Outreach through solar providers and trusted channels will be important for awareness of this service. Banks were viewed as inflexible, void of compassion, and nonnegotiable. In contrast, solar shops were often described as small businesses with potential for negotiation on price and loan agreements. For this reason it seems appropriate to start with solar shop relations and staff training rather than a financial institution. However, due to the potentially low familiarity with solar brands, outreach through trusted channels like community members might be more impactful.

\section{Limitations and Future Work}

The solar financing environment and partnerships add layers of complexity to this design. Every partnership and region will have specific requirements that will shape this model. It is important to acknowledge that we explored just one of several potential flows that need to be designed and evaluated.

We evaluated the case where the borrower has an account with the telecommunications company and bank institution, but has not yet provided consent to share data with third party partners. There are at least three more potential flows: 1) the borrower does not have accounts with the organizations involved and will need to sign up 2) the borrower has one of two accounts required, will need to sign up for the other, and provide consent 3) the borrower has both accounts, has already provided consent to share data with third party partners, and will be evaluated for the loan.

The authorization request would benefit from iterative research to fine tune the final text. Developing staff training and evaluating a sales program that removes conflicting interests will be imperative for a successful loan approval process.

\section{CONCLUSION}

We have evaluated the concept and explored limitations of the USSD loan approval model. This work emphasizes the need for ensuring the concept is thoroughly explained so users can give informed consent, training staff appropriately, and designing for various use cases to reduce the likelihood of false negative loan approvals. Given the prevalence of mobile and interest in energy connectivity, we believe a widely adaptable tool like USSD has notable potential for accelerating solar adoption.

\section{ACKNOWLEDGMENTS}

Thank you to the field team of ten who took time to travel to Uganda, interview participants, and make contributions in the multiday workshop analysis. 


\section{REFERENCES}

1. Nicola J. Bidwell, Masbulele Siya, Gary Marsden, William D. Tucker, M. Tshemese, N. Gaven, S. Ntlangano, Simon Robinson, Kristen ALI Eglinton. 2013. Walking and the social life of solar charging in rural Africa. In ACM Transactions on ComputerHuman Interaction (TOCHI '13), v.20 n.4, p.1-33. http://dx.doi.org/10.1145/2509404.2493524

2. Daniel Björkegren, Darrell Grissen, 2015. Behavior Revealed in Mobile Phone Usage Predicts Loan Repayment. Social Science Research Network (SSRN), 2611775.

3. Christian Etzensperger. Research Insight The Microfinance Revolution in East Africa. 2013. Retrieved February 20, 2016 from http://www.responsability.com/data/docs/en/1684/Rese arch-Insight-MF-Revolution-in-East-Africa.pdf

4. Stephen Karekezi, Susan McDade, Brenda Boardman, John Kimani and Nora Lustig. 2014. Energy, Poverty, and Development. Laxenburg Austria: International Institute for Applied Statistical Analyses (IIASA). DOI: 9781107005198

5. Robert Kinyera. 2016. Causes of high default rate on loans in commercial banks: A case study of Centenary Bank LTD-Kampala Capital City. Unpublished masters research paper. Makerere University, Kampala, Uganda.

6. Ignacio Mas and Dan Radcliffe. 2010. Scaling mobile money. Journal of Payments Strategy \& Systems 5, 3:298-315.

7. Ministry of Foreign Affairs of Denmark. 2014. Access to Finance. Retrieved March 7, 2016 from http://um.dk/search?q=annual\%20report\%202014\&filt er $=0$

8. Olga Morawczynski. 2009. Examining the usage and impact of transformational M-banking in Kenya. In Internationalization, Design and Global Development (IDGD '09), 495-504.

9. Olga Morawczynski and Mark Pickens. 2009. Poor People Using Mobile Financial Services: Observations on Customer Usage and Impact from M-Pesa. Retrieved February 19, 2015 from https://www.cgap.org/sites/default/files/CGAP-BriefPoor-People-Using-Mobile-Financial-ServicesObservations-on-Customer-Usage-and-Impact-fromM-PESA-Aug-2009.pdf
10. David Musiime and Peter Goldstein. 2014. Uganda Quick Insights Report. Retrieved August 20, 2015 from http://finclusion.org/wpcontent/uploads/2014/03/FIIUganda-Wave-1-PublicQuant-QuickSights.pdf

11. Baraka Nyamtiga, Anael Sam, and Loserian Laizer. 2013. Conducting Mobile Transactions: A Case Study Of Tanzania. International Journal of Technology Enhancements and Emerging Engineering Research 1, 3: 2357-4289.

12. Saurabh Panjwani, Edward Cutrell. 2010. Usably secure, low-cost authentication for mobile banking. In Proceedings of the Sixth Symposium on Usable Privacy and Security (SOUPS '10).

http://dx.doi.org/10.1145/1837110.1837116

13. Trevor Perrier, Brian DeRenzi, Richard Anderson. 2015. USSD: The Third Universal App. In Proceedings of the Annual Symposium on Computing for Development (ACM DEV '15). http://dx.doi.org/10.1145/2830629.2830645

14. Claire Scharwatt, Arunjay Katakam, Jennifer Frydrych, Alix Murphy, and Nika Naghavi. 2014. State of the Industry Mobile Financial Services for the Unbanked. Retrieved November 7, 2015 from http://www.gsma.com/mobilefordevelopment/wpcontent/uploads/2015/03/SOTIR_2014.pdf

15. United Nations. 2015. The Sustainable Development Goals Report 2015. New York City, NY: United Nations (UN). DOI: 978-92-1-101320-7

16. World Bank. 2015. Access to electricity (\% of population). Retrieved April 25, 2016 from http://data.worldbank.org/indicator/EG.ELC.ACCS.ZS/

17. World Bank. 2016. Doing Business 2016: Measuring Regulatory Quality and Efficiency. Washington, DC: World Bank Group. DOI: 10.1596/978-1-4648-0667-4

18. World Bank. 2015. Financial Inclusion Data / Global Findex. Retrieved April 25, 2016 from http://datatopics.worldbank.org/financialinclusion/coun try/uganda

19. World Bank. 2015. Global Tracking Framework. Retrieved January 11, 2016 from https://www.iea.org/media/freepublications/oneoff/Glo balTrackingFrameworkOverview.pdf 